\title{
Modelling the energy systems in a PV powered two floor desert ZEH
}

\author{
M. A. Serag-Eldin \\ American University in Cairo, Egypt
}

\begin{abstract}
The paper presents an integral computational model for the prediction of the thermal performance of a conceptual two-floor, zero energy house (ZEH) in the Arabian desert. The ZEH is powered by PV modules which shade the roof during the day time and retract at night to expose it the sky, thus enhancing night time cooling. The house boasts all modern comforts, including air-conditioning. Solar radiation models coupled with recently published ASHRAE environmental data and models are integrated with a time dependent heat conduction model to predict the heating and cooling loads, for given equipment and storage characteristics. The application of the computational model is demonstrated by employing it to predict the effect of various design parameters on performance and equipment sizing, for a typical desert site in the Kingdom of Saudi Arabia. Keywords: zero-energy-house, solar energy, desert environment, sustainability, modelling.
\end{abstract}

\section{Introduction}

The paper is concerned with the presentation and application of an efficient computational model for the investigation of the thermal performance of the integrated energy systems in a modern two floor, zero energy house (ZEH) located in the Arabian desert. Solar energy drives the whole energy system after being converted to electrical energy employing roof mounted PV modules. Several investigations have been reported in the past for single floor, roof mounted ZEH designs, e.g. Serag-Eldin [1] and Beshr et al. [2], as they are much less challenging to meet the zero external energy requirement than for two floor houses. A two floor ZEH design was considered by Serag-Eldin [3], however synthetic data was used for solar radiation and environmental properties and only 
a crude presentation of long-wave atmospheric radiation was employed. SeragEldin [4] demonstrated the importance of accurate site data on prediction of performance; moreover the success of the present design depends to a large extent on night-time cooling by atmospheric radiation. Thus the need arose for more precise and site specific data, particularly in view of the delicate balance between supply and demand for two floor buildings. These issues are addressed in the present work.

The paper first describes the various models comprising the computational model; these include solar radiation and environmental models, a long-wave atmospheric radiation model, and equipment characteristics models. It then demonstrates use of the computational model by analyzing the impact of each of, the percentile design factor, room temperature, cooling-air peak temperature reduction by evaporative-cooling, heat exchange between fresh-air and discharge air, and COP characteristics, on the cooling load and equipment capacities.

\section{Problem specification and description of ZEH}

The home under consideration lies on a secluded desert plot in Dhahran, KSA, whose elevation is $17 \mathrm{~m}$ above sea-level, and whose angle of latitude is $26.27^{0}$ North. The house features two floors, each $3.3 \mathrm{~m}$ high, with a ground foot print of $16.5 \mathrm{~m} \mathrm{x} 16.5 \mathrm{~m}$. The roof-top displays $1 \mathrm{~m}$ overhangs on each side, in addition to top and side-shades surrounding each window. The window heights are each $1.5 \mathrm{~m}$, and the total window area is $15 \%$ of total envelope area, assumed uniformly distributed. The windows display a $\mathrm{U}$-value of $3.1 \mathrm{~W} / \mathrm{m}^{2} \mathrm{~K}$ and a solar heat gain coefficient $\mathrm{F}=0.71$.

During day time, the roof-top is covered by a reflective cover and Photovoltaic modules, about $0.2 \mathrm{~m}$ above the roof top, so as to totally shade the roof from solar radiation, whilst simultaneously collecting solar energy; during night time both the modules and cover are retracted to expose the roof top to the sky immediately above it, thus enhancing night time cooling, which is substantial in desert environments. The roof also includes good insulation material to reduce heat transfer to the indoors.

The building side walls comprise a $0.06 \mathrm{~m}$ external sandstone cladding, followed by two $0.12 \mathrm{~m}$ red brick walls separated by a 0.01 to $0.05 \mathrm{~m}$ air gap. Research has shown that due to the appearance of natural convection effects for air-gaps greater than $0.01 \mathrm{~m}$, the overall thermal resistance in this range is almost constant, Kreider and Rabl [5]; hence calculations are made here for conductive resistance only, with a representative air gap of $0.01 \mathrm{~m}$; however in practical implementation a $0.05 \mathrm{~m}$ air gap would be more realizable. The internal wall is covered by a $0.03 \mathrm{~m}$ layer of plaster. The roof surface comprises a lower $0.02 \mathrm{~m}$ plaster layer, above which is a $0.12 \mathrm{~m}$ concrete layer, covered by $0.10 \mathrm{~m}$ of mortar and asbestos insulation, followed by a $0.06 \mathrm{~m}$ thick layer of gravel. The surrounding ground short wave reflectivity is assumed to be 0.25 .

The room temperature is maintained constant by an electrically driven conventional air-conditioning system, which runs straight off the output of the $\mathrm{PV}$ modules during day time, and extracts power from battery storage during 
night time. Displacement ventilation, e.g. Serag-Eldin [6], is employed to maintain air quality with reduced fresh-air rates ( 0.5 air-exchanges $/ \mathrm{h})$. The house is built to a high level of tightness, so that a 0.35 air-exchanges/h infiltration rate is expected. The conversion efficiency of the photovoltaic cells, $\eta_{\mathrm{c}}$ is assumed to be $15 \%$ at source; moreover an average combined electrical storage and distribution efficiency of $70 \%$ is assumed. The nominal number of occupants is 7; the electrical light-load is estimated to be $1 \mathrm{~kW}$ maintained uniformly over all night-time hours, whereas the total auxiliary electrical loads (washing machines, TV sets, computers,..) are expressed by a uniform $980 \mathrm{~W}$ load maintained over the $24 \mathrm{~h}$. The latter two numbers were derived from considerations of the experimental and theoretical work of NAHB Research Center [7], after adapting them to the present house specifications following the procedure described by Serag-Eldin [1].

\section{Mathematical models}

The basic models employed comprise a solar radiation model, an environmental model, a heat conduction model, and an air-conditioning COP model; they are each presented here in turn.

\subsection{The Solar radiation model}

The solar beam angles are determined by first deriving the declination angle $\delta$ (degrees) for any day of the year from:

$$
\delta=23.45^{\circ} \sin \left(2 \pi\left(\frac{(n+284)}{365.25}\right)\right.
$$

where $\mathrm{n}$ is the number of the day of the year measured from January $1^{\text {st }}$.

Next the sun beam incidence (Zenith) angle $\theta_{\mathrm{s}}$ on a horizontal plane is calculated from:

$$
\cos \theta_{s}=\cos \lambda \cdot \cos \delta \cdot \cos \omega+\sin \lambda \cdot \sin \delta
$$

where $\omega$ is the solar angle. The sunset angle $\omega_{\mathrm{ss}}$ is given by

$$
\cos \omega_{s s}=-\tan \lambda \cdot \tan \delta
$$

The azimuth angle from due South, $\varphi_{\mathrm{s}}$, is determined uniquely from the two equations:

$$
\sin \varphi_{s}=\frac{\cos \delta \cdot \sin \omega}{\sin \theta_{s}}
$$

and

$$
\cos \phi_{s}=\frac{\cos \omega \cdot \cos \delta \cdot \sin \lambda-\sin \delta \cdot \cos \lambda}{\sin \theta_{s}}
$$

For a vertical wall, incidence angle is given by:

$$
\cos \theta_{i}=\sin \theta_{s} \cdot \cos \left(\varphi_{s}-\varphi_{w}\right)
$$


where $\varphi_{W}$ is the azimuth orientation of the wall from due South.

Solar radiation is composed of two components, a direct (beam) component, $\mathrm{I}_{\text {dir }}$, and a diffuse component, $\mathrm{I}_{\text {diff. }}$ They are derived from the following two empirical equations:

$$
I_{d i r}=I_{0} e^{-\left[\tau_{b} m^{b}\right]}
$$

and

$$
I_{\text {dif }}=I_{0} e^{-\left[\tau_{d} m^{d}\right]}
$$

where $\tau_{\mathrm{b}}$ and $\tau_{\mathrm{d}}$ are site specific values which vary over the year and are obtained from long period meteorological measurements; values of $\tau_{\mathrm{b}}$ and $\tau_{\mathrm{d}}$ are reported by ASHRAE [8] for more than 4000 sites world-wide, on the $21^{\text {st }}$ day of each month. The mass exponents $b$ and $d$ are correlated to $\tau_{\mathrm{b}}$ and $\tau_{\mathrm{d}}$ through the following equations:

$$
\begin{gathered}
b=1.219-0.043 \tau_{b}-0.151 \tau_{d}-0.204 \tau_{b} \tau_{d} \\
\text { and } \\
d=0.202+0.852 \tau_{b}-0.007 \tau_{d}-0.357 \tau_{b} \tau_{d}
\end{gathered}
$$

$\mathrm{I}_{0}$ is solar irradiance outside atmosphere at normal incidence expressed by the following equation:

$$
I_{0}=1367\left[1+0.033 \cos \left(360^{\circ}(n-3) / 365\right)\right]
$$

and $m$ is the relative air-mass ratio, representing the actual mass of atmosphere in the sun-to-earth path to that which would exist if the sun were directly overhead. It is a pure function of solar angle and is calculated from the following equation:

$$
m=\frac{1}{\cos \theta_{s}+0.50572\left(6.07995+\left(90-\theta_{s}\right)^{-1.6364}\right.}
$$

The total incident radiation on a horizontal surface, $\mathrm{I}_{\mathrm{glo}, \mathrm{hor}}$, is expressed by:

$$
I_{g l o, h o r}=I_{d i r} \cos \theta_{s}+I_{d i f f}
$$

The total solar energy, $I_{g l o \text {, vert }}$ received at a vertical wall is expressed by:

$$
I_{\text {glo,vert }}=I_{d i r} \cos \theta_{i}+I_{g l o, h o r} \rho_{g} / 2+\max \left(0.45,0.55+0.437 \cos \theta_{i}+0.313 \cos ^{2} \theta_{i}\right) I_{d i f f}
$$

where $\rho_{G}$ is the ground reflectivity. The first term on the right hand side presents the beam radiation contribution, the second the ground reflected solar radiation, whereas the last one presents the non-isotropic diffuse radiation; the anisotropy is caused by some parts of the sky being brighter than others. 


\subsection{Heat conduction model}

Heat is transferred across the solid medium (walls, roof and glazing) by conduction, mainly in the direction normal to the solid surface, $\mathrm{x}$. Therefore, the temperature $\mathrm{T}$ and heat fluxes are obtained by numerical solution of the following unsteady heat conduction equation through the solid mediums of density $\rho$, conductivity, $\mathrm{k}$, and specific heat $\mathrm{c}$ :

$$
\frac{\partial}{\partial t}(\rho c T)=\frac{\partial}{\partial x}\left(k \frac{\partial T}{\partial x}\right)
$$

subject to boundary conditions which express heat convection with environment and both solar and long-wave radiation exchange with the environment and nearby surfaces. Heat transfer coefficients are estimated from appropriate empirical relations adopting a nominal free wind velocity $V=3 \mathrm{~m} / \mathrm{s}$.

The control-volume method is employed to derive the solution of the heat conduction differential equation, using second order differencing in both space and time. A total of 360 control-volumes were employed across the side walls and ceiling surface. A time step of 0.05 hours was adopted for the final runs. Grid-dependence tests showed no variations within at least 4 significant figures. Because of the non-linearities associated with the radiation terms at the external surfaces, air gaps and room boundaries, iteration is necessary. Moreover, to truly reach 24 hour (day) periodicity, and eliminate effect of initial (starting solution) temperatures, many repetitions are necessary. Iteration for non-linearity and cycle repetitions were handled simultaneously in the solution algorithm, by successively repeating the calculations of a full day, each time starting with the previous day results. Cycle repetitions were stopped only after maximum changes in temperature values were all within 6 significant figures.

\subsection{Environmental models}

These are classified here as two models, as follows:

\subsubsection{Ambient temperatures model}

For thousands of meteorological sites, ASHRAE [8] provides fairly detailed climatic design conditions which may be used to interpolate hourly variation of wet bulb and dry bulb temperatures. Since it is not practical to design for extreme conditions which occur very infrequently (e.g. highest dry bulb temperature in 50 years), practical HVAC design caters for meeting comfort conditions for all but a specified percentage of the year. ASHRAE provides design values for $0.4 \%, 2 \%, 5 \%$ and $10 \%$ percentiles, corresponding to 35,175 , 438 and $876 \mathrm{~h}$ per year, respectively. For a specified design percentile, the procedure for estimating the instantaneous temperature profiles is as follows:

i- the monthly design dry bulb temperature $T_{d b}$, coincident wet bulb temperature $T_{w b}$, and their mean daily temperature ranges, $T_{d b-r}, T_{w b-r}$, respectively, are read from the ASHRAE table for the specified location. 
Since cooling load is considered, $\mathrm{T}_{\mathrm{db}}$ represents the peak daily temperature $\mathrm{T}_{\mathrm{db}, \max }$ to be employed in cooling load calculations. Like-wise, $\mathrm{T}_{\mathrm{wb}}$ represents $T_{w b, m a x}$.

ii- the hourly values of $T_{d b}$ and $T_{w b}$ are calculated from:

$$
\begin{gathered}
\mathrm{T}_{\mathrm{db}}=\mathrm{T}_{\mathrm{db}, \text { max }}-\beta \mathrm{T}_{\mathrm{db}-\mathrm{r}} \\
\quad \text { and } \\
\mathrm{T}_{\mathrm{wb}}=\mathrm{T}_{\mathrm{wb}, \text { max }}-\beta \mathrm{T}_{\mathrm{wb}-\mathrm{r}}
\end{gathered}
$$

where $\beta$ is a daily temperature profile shape factor which varies between 0 and 1 [8]; Hedrick [9] and Thevenard [10] showed it to represent accurately both dry-bulb and wet bulb temperature variations on design days.

iii- instantaneous values are interpolated from hourly values using cubic splines.

iv- the instantaneous dew-point temperatures $\mathrm{T}_{\mathrm{dp}}$ in ${ }^{0} \mathrm{C}$, are derived from the instantaneous values of $\mathrm{T}_{\mathrm{db}}$ and $\mathrm{T}_{\mathrm{wb}}$ employing the following psychrometric relations:

$$
\begin{gathered}
\mathrm{T}_{\mathrm{dp}}=6.54+14.526 \ln \mathrm{p}_{\mathrm{w}}+0.7389\left(\operatorname{lnp}_{\mathrm{w}}\right)^{2}+0.09486\left(\ln \mathrm{p}_{\mathrm{w}}\right)^{3}+0.4569 \mathrm{p}_{\mathrm{w}}{ }^{0.1984} \\
\mathrm{~T}_{\mathrm{dp}}=6.09+12.608 \operatorname{lnp}_{\mathrm{w}}+0.4959\left(\operatorname{lnp}_{\mathrm{w}}\right)^{2} \\
\mathrm{~T}_{\mathrm{dp}}<0
\end{gathered}
$$

where $\mathrm{p}_{\mathrm{w}}$ is the water vapour partial pressure in the air, $\mathrm{kPa}$. It is related to the humidity ratio $\mathrm{W}$ through the relation:

$$
\mathrm{p}_{\mathrm{w}}=\mathrm{W} \mathrm{p} /(0.621945+\mathrm{W})
$$

where $\mathrm{p}$ is the atmospheric air pressure, $\mathrm{kPa}$, and $\mathrm{W}$ is derived from:

$$
\begin{aligned}
& \mathrm{W}=\left[\left(2830-0.24 \mathrm{~T}_{\mathrm{wb}}\right) \mathrm{W}_{\mathrm{s}}\left(\mathrm{T}_{\mathrm{wb}}\right)-1.006\left(\mathrm{~T}_{\mathrm{db}}-\mathrm{T}_{\mathrm{wb}}\right)\right] /\left[2830+1.86 \mathrm{~T}_{\mathrm{db}}-2.1 \mathrm{~T}_{\mathrm{wb}}\right] \\
& \mathrm{T}_{\mathrm{db}}<0 \\
& \mathrm{~W}=\left[\left(2501-2.326 \mathrm{~T}_{\mathrm{wb}}\right) \mathrm{W}_{\mathrm{s}}\left(\mathrm{T}_{\mathrm{wb}}\right)-1.006\left(\mathrm{~T}_{\mathrm{db}}-\mathrm{T}_{\mathrm{wb}}\right)\right] /\left[2501+1.86 \mathrm{~T}_{\mathrm{db}}-4.186 \mathrm{~T}_{\mathrm{wb}}\right]
\end{aligned}
$$

where $\mathrm{W}_{\mathrm{s}}\left(\mathrm{T}_{\mathrm{wb}}\right)$ is saturation humidity ratio at $\mathrm{T}_{\mathrm{wb}}$. It is related to $\mathrm{p}_{\mathrm{ws}}$ at wetbulb temperature $\mathrm{p}_{\mathrm{ws}}\left(\mathrm{T}_{\mathrm{wb}}\right)$ through the relation:

$$
\mathrm{W}_{\mathrm{s}}\left(\mathrm{T}_{\mathrm{wb}}\right)=0.621945 \mathrm{p}_{\mathrm{ws}}\left(\mathrm{T}_{\mathrm{wb}}\right) /\left(\mathrm{p}-\mathrm{p}_{\mathrm{ws}}\left(\mathrm{T}_{\mathrm{wb}}\right)\right)
$$

the latter is obtained from :

$$
\begin{array}{ll}
\ln \left[\mathrm{p}_{\mathrm{ws}}\left(\mathrm{T}_{\mathrm{wb}}\right)\right]=\mathrm{C}_{1} / \mathrm{T}_{\mathrm{wb}}+\mathrm{C}_{2}+\mathrm{C}_{3} \mathrm{~T}_{\mathrm{wb}}+\mathrm{C}_{4} \mathrm{~T}_{\mathrm{wb}}{ }^{2}+\mathrm{C}_{5} \mathrm{~T}_{\mathrm{wb}}{ }^{3}+\mathrm{C}_{6} \mathrm{~T}_{\mathrm{wb}}{ }^{4}+\mathrm{C}_{7} \ln \mathrm{T}_{\mathrm{wb}} \\
\ln \left[\mathrm{p}_{\mathrm{ws}}\left(\mathrm{T}_{\mathrm{wb}}\right)\right]=\mathrm{C}_{8} / \mathrm{T}_{\mathrm{wb}}+\mathrm{C}_{9}+\mathrm{C}_{10} \mathrm{~T}_{\mathrm{wb}}+\mathrm{C}_{11} \mathrm{~T}_{\mathrm{wb}}{ }^{2}+\mathrm{C}_{12} \mathrm{~T}_{\mathrm{wb}}{ }^{3}+\mathrm{C}_{13} \ln \mathrm{T}_{\mathrm{wb}} & \mathrm{T}_{\mathrm{wb}} \geq 0
\end{array}
$$

where $T_{w b}$ is expressed in $K$ and $C_{1} . . C_{13}$ are constants whose values are displayed in Table 1. 
Table 1: Constants for $\mathrm{p}_{\mathrm{ws}}$ calculation.

\begin{tabular}{|c|c|c|c|c|c|c|c|c|c|c|c|c|}
\hline$C_{1}$ & $\mathrm{C}_{2}$ & $\mathrm{C}_{3}$ & $\mathrm{C}_{4}$ & $\mathrm{C}_{5}$ & $\mathrm{C}_{6}$ & $C_{7}$ & $\mathrm{C}_{8}$ & $\mathrm{C}_{9}$ & $C_{10}$ & $C_{11}$ & $C_{12}$ & $\mathrm{C}_{13}$ \\
\hline $\begin{array}{l}n \\
\frac{\pi}{6} \\
\stackrel{n}{r}\end{array}$ & $\begin{array}{l}\text { న్ } \\
\text { ஸె }\end{array}$ & $\begin{array}{l}\infty \\
\hat{\sigma} \\
0\end{array}$ & 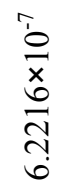 & 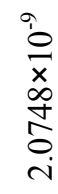 & 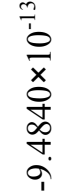 & $\begin{array}{l}\mathscr{n} \\
\underset{\sigma}{+} \\
\stackrel{+}{*}\end{array}$ & 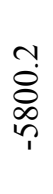 & $\frac{n}{\stackrel{n}{n}}$ & 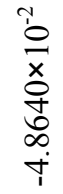 & 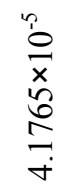 & 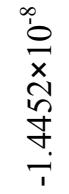 & 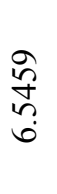 \\
\hline
\end{tabular}

\subsubsection{Atmospheric radiation model}

Long wave radiation exchange between roof and sky, known as atmospheric radiation, is a key factor in the success of the proposed ZEH. Therefore accurate estimate of its magnitude is of high importance. The net long-wave radiation exchange between roof and sky $\mathrm{q}_{\mathrm{rs}}$ is expressed by the term:

$$
\mathrm{q}_{\mathrm{rs}}=\varepsilon_{\mathrm{r}} \sigma\left(\mathrm{T}_{\mathrm{r}}^{4}-\varepsilon_{\mathrm{a}} \mathrm{T}_{\mathrm{a}}^{4}\right)
$$

where $\varepsilon_{\mathrm{r}}$ is the long wave emissivity of the roof surface or PV/cover material, $\mathrm{T}_{\mathrm{r}}$ is the temperature of the roof surface or PV/cover material and $\mathrm{T}_{\mathrm{a}}$ is the ambient temperature. Whereas $\varepsilon_{\mathrm{a}}$ is the apparent emissivity of the atmosphere, according to Bliss [11] and ASHRAE [12]; it is defined as the ratio of the atmospheric radiation on a horizontal surface per unit area to $\left(\sigma \mathrm{T}_{\mathrm{a}}^{4}\right)$, and is only a function of $\mathrm{T}_{\mathrm{dp}}$ near ground. The latter is derived as shown in the previous section. Values of $\varepsilon_{\mathrm{a}}$ at given $\mathrm{T}_{\mathrm{dp}}$ increments were deduced from Bliss's graphical display, then cubic splines were used to interpolate intermediate values.

\subsection{Air conditioning model}

In a desert environment water is scarce; hence cooling of the air conditioning system condenser must rely primarily on ambient air. The COP of the airconditioning system suffers heavily with a rise of cooling media temperature; indeed some vapour compression systems will shut down at ambient air temperatures above $45^{\circ} \mathrm{C}$ to protect themselves. However peak summer temperatures in the desert often reach $50^{\circ} \mathrm{C}$.

Thus for exceptionally hot summer days, it is proposed here to use small amounts of water for cooling of condenser coils by misting and evaporative cooling; just enough to reduce the effective cooling air temperature to an upper limit, $\mathrm{T}_{\mathrm{ul}}$. This water need not be potable, and may be the accumulated output of treatment of residential waste water, stored over a long period of time (extending to cooler seasons if need be). The model employed here allows the calculation of the daily cooling water usage for a pre-set $T_{u l}$. Setting $T_{u l}$ above ambient temperature naturally deactivates this feature.

Whereas different models and makes display different COP characteristics, two characteristic profiles are considered here, one based on the average of currently operating European residential units, ECODESIGN [13], and the other a state of the art unit displaying an electronically controlled expansion valve, EEV [14]. The two characteristics are displayed simultaneously in Fig. 1. 


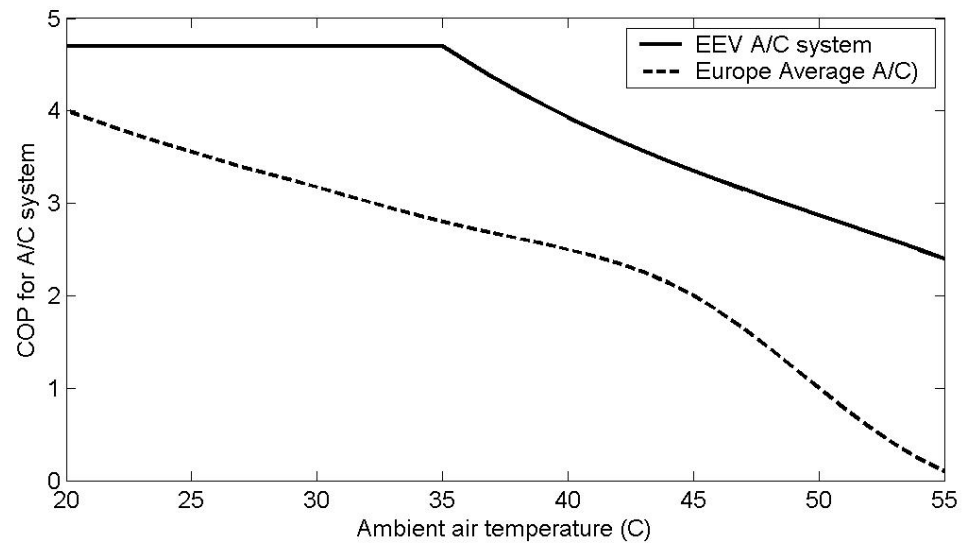

Figure 1: $\quad$ COP for EEV and European average.

In order to reduce cooling load, the fresh air is cooled prior to entering indoors by exhaust air leaving at room temperature, in a counter flow heat exchanger. Thus the sensible heat load is reduced, the gain increasing with increase of outdoor temperature. Since the heat capacity of the return air is at least as large as that of the fresh air(actually larger because of infiltration), theoretically it is possible in a very long double pipe heat exchanger to cool the fresh air down to room temperature and eliminate this component of the sensible heat load altogether. However, for practical reasons a relatively short heat exchanger is employed and it is assumed that the effectiveness of the heat exchanger, $\varepsilon_{\mathrm{HX}}=0.7$; i.e. $70 \%$ of cooling of fresh air occurs in heat exchanger.

\section{Results}

Figures 2-3 present results of the basic case, which employs a $2 \%$ design factor, the EEV COP characteristic, evaporative cooling on exceptionally hot days to reduce peak cooling air temperature to $43^{\circ} \mathrm{C}$, and room temperatures of $25^{\circ} \mathrm{C}$ and $22^{\circ} \mathrm{C}$ for June and December months, respectively; without cooling of freshair via a heat exchanger. They display the distribution of the cooling loads for the envelope walls, windows and auxiliary loads (fresh air, persons, infiltration, equipment, ..) as well as their sum, for June $21^{\text {st }}$ and December $21^{\text {st }}$, respectively.

Table 2 displays the results of various parameters on cooling load electricity consumption (kW.h/day), auxiliary appliances and lighting electrical loads (kW.h/day), and the total daily output of the PV modules (kW.h/day). It also displays the required equipment rating for each case, namely battery storage capacity $(\mathrm{kW} . \mathrm{h})$, PV module capacity $(\mathrm{kW})$ and the cooling equipment rating $(\mathrm{kW})$. The first three rows display results of the basic design case for three key days representing spring/autumn, summer and winter. It is apparent that equipment rating depends only on the requirements of June $21^{\text {st }}$; only $69.8 \%$ of the roof area is required to be covered by PV modules for June $21^{\text {st }}$, which still leaves ample roof area for other equipment. 


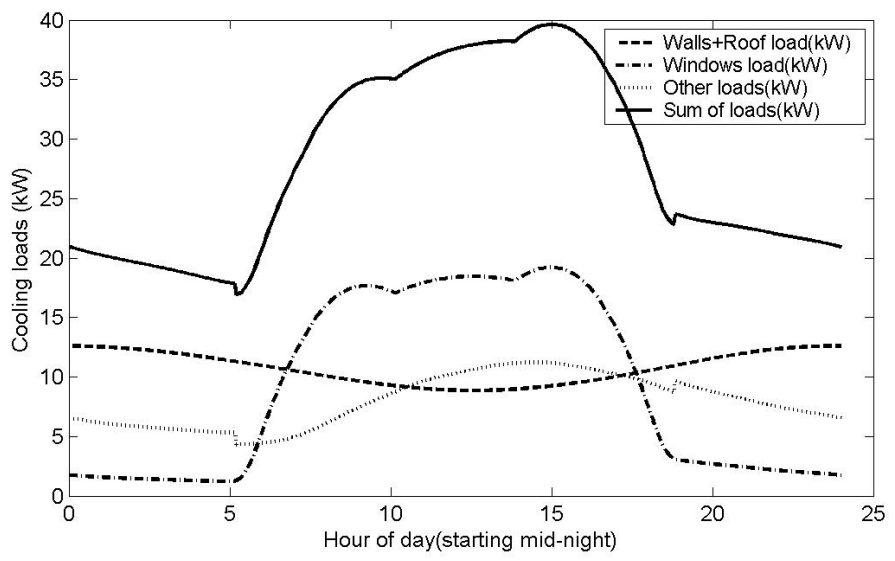

Figure 2: $\quad$ Cooling loads on June $21^{\text {st }}$.

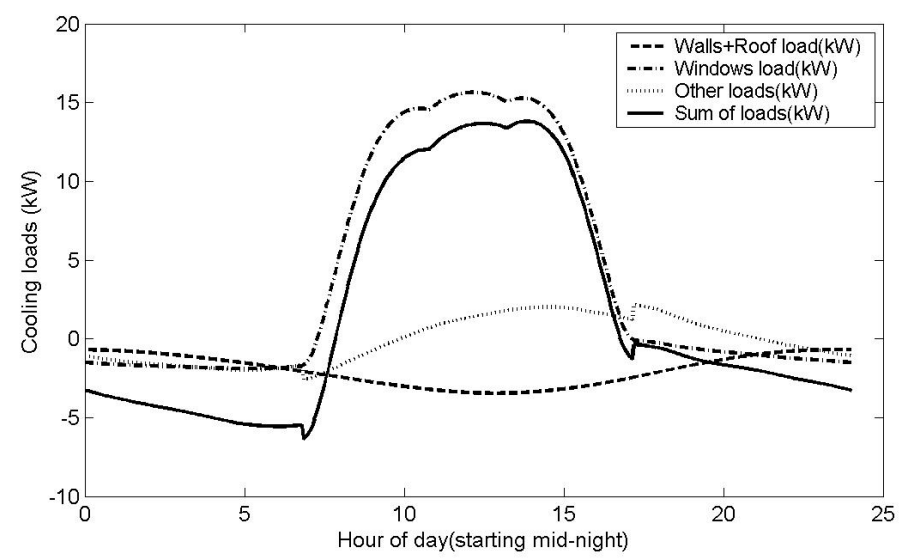

Figure 3: Cooling loads on December $21^{\text {st }}$.

Rows 4-6 display the above results for June $21^{\text {st }}$, for 3 different ASHRAE design percentile values, namely $0.4 \%, 2 \%$ and $5 \%$. The lower the percentile value the higher the peak values of the ambient temperature; hence the larger the heat gain by convection at the envelope surface, sensible heat of fresh-air and infiltration, and long-wave atmospheric radiation. Thus the cooling load increases from $592 \mathrm{~kW} . \mathrm{h} /$ day for $5 \%$, to $635 \mathrm{~kW} . \mathrm{h} /$ day for $2 \%$, to $691 \mathrm{~kW} . \mathrm{h} /$ day for $0.4 \%$, corresponding to cooling equipment capacities of $36.5 \mathrm{~kW}, 38.3 \mathrm{~kW}$ and $40.6 \mathrm{~kW}$, respectively. Although, the basic case calculations employ $2 \%$, as this is the more common practice, using a $5 \%$ value is justified here since our calculations assume that the design day conditions are continuously repeating themselves every 24 hours; whereas in reality the previous day should be cooler since the design criteria are for the hottest day of the month. Since our building 
Table 2: $\quad$ Effect of design parameters on loads and equipment capacities.

\begin{tabular}{|c|c|c|c|c|c|c|c|}
\hline 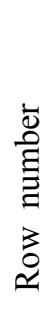 & Case Description & 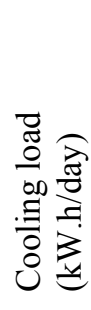 & 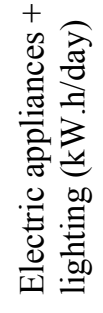 & 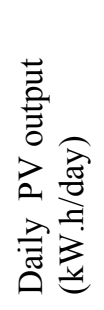 & 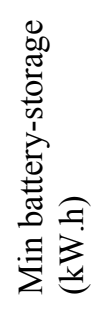 & 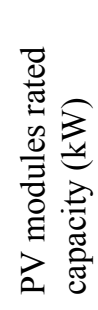 & 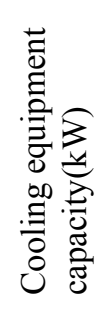 \\
\hline 1 & base case, March $21^{\text {st }}$ & 372.7 & 35.6 & 115.6 & 53.6 & 26.5 & 28 \\
\hline 2 & base case, June $21^{\text {st }}$ & 668.7 & 33.87 & 197.2 & 83.8 & 36.4 & 39.6 \\
\hline 3 & base case, Dec. $21^{\text {st }}$ & 91.9 & 37.2 & 65.3 & 36.3 & 25.7 & 13.8 \\
\hline 4 & cent, $0.4 \%$ & 691.4 & 33.87 & 206.5 & 88.3 & 39.1 & 40.6 \\
\hline 5 & design percent, $2.0 \%$ & 634.8 & 33.87 & 189.2 & 80.0 & 35.8 & 38.3 \\
\hline 6 & design percent, $5.0 \%$ & 592.0 & 33.87 & 176.0 & 73.9 & 33.3 & 36.5 \\
\hline 7 & cooling-air limit $40^{\circ}$ & 634.8 & 33.87 & 183.3 & 79.4 & 34.7 & 38.3 \\
\hline 8 & cooling-air limit $43^{0}$ & 634.8 & 33.87 & 189.2 & 80.0 & 35.8 & 38.3 \\
\hline 9 & cooling-air limit $46^{0}$ & 634.8 & 33.87 & 190.6 & 79.9 & 36.1 & 38.3 \\
\hline 10 & room temp. $23^{0} \mathrm{C}$ & 700.8 & 33.87 & 204.9 & 87.7 & 38.8 & 41.1 \\
\hline 11 & room temp. $25^{\circ} \mathrm{C}$ & 634.8 & 33.87 & 189.2 & 80.0 & 35.8 & 38.3 \\
\hline 12 & room temp. $27^{0} \mathrm{C}$ & 568.7 & 33.87 & 173.5 & 72.2 & 32.9 & 35.5 \\
\hline 13 & COP Europe average & 634.8 & 33.87 & 279 & 113. & 52.9 & 38.3 \\
\hline 14 & COP of EEV A/C & 634.8 & 33.87 & 189.2 & 80.0 & 35.8 & 38.3 \\
\hline 15 & $\mathrm{EEV}+$ fresh-air HE & 579.8 & 33.87 & 175.5 & 74.8 & 33.2 & 34.5 \\
\hline
\end{tabular}

envelope displays exceptionally high thermal capacity, the effect of a cooler previous day on cooling loads is to reduce cooling load considerably.

Rows 7-9 reveal the variation of equipment capacities and loads with variation of allowable peak cooling-air temperatures, controlled by using small amounts of evaporative cooling to lower ambient temperature to the designated peak values. The lowering of peak cooling air temperature affects only the size of equipment, via raising the COP, but has no bearing on the cooling loads. The maximum ambient air temperature for this design day is $44.5^{\circ} \mathrm{C}$ occurring at 14.5 hour solar time. Thus no lowering of ambient air peak temperature occurs with a peak cooling air temperature of $46^{\circ} \mathrm{C}$. The water consumption rate for the $43^{\circ} \mathrm{C}$ and $40^{\circ} \mathrm{C}$ peaks are $69.2 \mathrm{~kg} / \mathrm{day}$, and $369.5 \mathrm{~kg} /$ day, respectively. It is apparent that the gains introduced by reducing the cooling air temperature peaks are small, unless the peaks are reduced substantially, in which case the water consumption may be unacceptably high; from a cooling perspective it may then be more efficient to use it in an indoor evaporative cooler. However, it may be required to restrict the peak cooling air temperature just to protect the cooling equipment and stopping it from shutting down. Thus a peak of $43^{\circ} \mathrm{C}$ is adopted for base case, which should correspond to a condenser temperature of around $48^{\circ} \mathrm{C}$. 
Rows 10-12 reveal the variation of equipment capacities and cooling load with specified internal room temperature for June $21^{\text {st }}$. As the room temperature rises from $23^{\circ} \mathrm{C}$ to $25^{\circ} \mathrm{C}$ and then to $27^{\circ} \mathrm{C}$, the cooling load decreases from 701 $\mathrm{kW} . \mathrm{h} /$ day, to $635 \mathrm{~kW} . \mathrm{h} /$ day and to $569 \mathrm{~kW} . \mathrm{h} /$ day, respectively; with corresponding drops in PV and cooling equipment capacities. This drop is substantial. A room temperature of $27^{\circ} \mathrm{C}$ in a desert environment may be quite acceptable since the relative humidity is exceptionally low; moreover, outdoor temperatures are exceptionally high in summer and hence local summer clothing is generally made of porous cotton and loose fitting; well adapted to high temperatures with low humidity.

Rows 13,14 show the effect of COP on performance, the two COP characteristics corresponding to the ones displayed in Fig. 1. The impact of COP on capacity of equipment (PV modules, battery and air-condition) is remarkable. For the European averaged COP, the required PV rated capacity is $53 \mathrm{~kW}$, whereas for the EEV COP the corresponding output is only $36 \mathrm{~kW}$. Adding an exhaust-air/fresh-air heat exchanger reduces the latter to $33 \mathrm{~kW}$. Since PV modules and battery storage are expensive items, it is expected to be well worth it to purchase state of the art, highly efficient air-conditioning systems. The last row presents results of using a fresh-air heat exchanger of effectiveness 0.7 on capacities; it produces an attractive 10\% saving in PV capacity alone.

Further savings may be introduced if clothes are dried outdoors rather than using an indoor electric clothes drier. According to [7] the energy consumed in clothes drying is at least $25 \%$ of the total $980 \mathrm{~W}$ estimated here, i.e. $245 \mathrm{~W}$. Indeed, a solar clothes drier [15] may even be employed to lower peak air temperatures. If the load for the internal electric clothes drier is removed, the basic case PV output will be reduced by about $6 \mathrm{~kW}$.h/day, i.e. $3 \%$.

\section{Summary and conclusion}

The paper presents a complete mathematical model for the prediction of the performance of a desert ZEH with roof mounted PV modules. The model makes use of ASHRAE meteorological data which is available for thousands of meteorological sites world-wide; thus reducing the need for prior site measurements.

The model is employed to investigate the effect of various design and operation parameters on the capacity of the PV modules, cooling equipment and battery storage. It is demonstrated that under optimum design conditions the capacity requirements may be reduced substantially over that of the basic design.

\section{Acknowledgements}

This work was funded by King Abdalla University for Science and Technology (KAUST) project on Integrated Desert Building Tech, grant held by AUC. 


\section{References}

[1] Serag_eldin, M.A., Thermal design of a modern, air-conditioned, singlefloor, solar-powered desert house, in press, Int. J. of Sustainable energy, 2011.

[2] Beshr, M., Khater, H. and Abdel Raouf, A., Modeling of a Residential Solar Stand-Alone Power System, Proc. of $1^{\text {st }}$ Int. Nuclear and Renewable Energy Conf., Amman, Jordan, March 21-24, 2010.

[3] Serag-Eldin, M.A., Thermal Design of a Modern, Two Floor, Zero Energy House in a Desert Compound, Proc. Thermal Issues in Emerging Technologies, Theta-3, Cairo, Egypt, Dec 19-22, 2010.

[4] Serag-Eldin, M.A., Influence of site on thermal design of a two floor ZEH in the desert, Theta-3 Conference, Cairo, December 19-21, 2010.

[5] Kreider, J. and Rabl, A. 1994, Heating and Cooling of Buildings: Design for Efficiency, McGraw-Hill Inc., New York, pp.257.

[6] Serag-Eldin, M.A., Displacement Ventilation for Efficient Air-conditioning and Ventilation of GYMs, Proc. of Heat-SET-2007 Conference, Chambery, France, 18-20 April, 2007, paper \# P-128.

[7] NAHB Research Center, Inc., "Zero Energy Home Armory Park Del Sol, Tucson, Arizona", Final report submitted to NREL, 1617 Cole Boulevard, Golden, CO 804101-3393, June 30 2004.

[8] ASHRAE Fundamentals Handbook, 2009, American Society of Heating, Refrigerating and Air-Conditioning Engineers, Inc., USA.

[9] Hedrick, R. Generation of Hourly Design-Day Weather Data (RP-1363). ASHRAE Research Project, Final Report, 2009.

[10] Thevenard, D. Updating the ASHRAE Climatic Data for Design and Standards, (RP -1453). ASHRAE Research Project Report, 2009.

[11] Bliss, R.W., Atmospheric Radiation Near the Surface of the Ground: A Summary for Engineers, Solar Energy 59(3), pp.103-120.

[12] ASHRAE HVAC Applications Handbook, 2007, American Society of Heating, Refrigerating and Air-Conditioning Engineers, Inc., USA.

[13] ECODESIGN-Preparatory Study on the Environmental Performance of Residential Room Conditioning Appliances, Draft report Task 4, July 2008, Contract TREND/D1/40-2005/LOT10/S07.56606.

[14] Chinnaraj, C. and Govindarajan, P., Performance Analysis of Electronic Expansion Valve in 1 TR Window Air Conditioner using Various Refrigerants, I. J. of Eng. Sc. and Tech., Vol. 2(9), 2010, 4020-4025.

[15] Suntivarakorn, P., Satmaromg, S., Benjapiyaporn, C. and Theerakulpisut, An experimental Study on Clothes Drying Using Waste Heat from Split Type Air Conditioner, World Academy of Sc., Eng. and Tech., 53, 2009, pp.168-173. 